\title{
SOCIO DEMOGRAPHIC AND CLINICAL PROFILE OF DIABETES MELLITUS IN ADOLESCENTS AND YOUNG ADULTS
}

Suresh $\mathrm{K}^{1}$, Maliyappa Vijay Kumar², Badrinath A. $\mathrm{K}^{3}$

\section{HOW TO CITE THIS ARTICLE:}

Suresh K, Maliyappa Vijay Kumar, Badrinath A. K. "Socio Demographic and Clinical Profile of Diabetes Mellitus in Adolescents and Young Adults". Journal of Evolution of Medical and Dental Sciences 2014; Vol. 3, Issue 09, March 3; Page: 2287-2301, DOI: 10.14260/jemds/2014/2138

ABSTRACT: OBJECTIVES: Objective of the study to find out the type of diabetes in diabetic patients whose age of onset $<35$ years by using ADA criteria, also to study about sociodemographic characters and their clinical presentations by clinical examination. RESEARCH DESIGNS AND METHODS: A total of 130 patients who developed diabetes before the age of 35 were included in this descriptive study. The aim of the study was to find out the different types of diabetes and their epidemiology and also to study the clinical abnormalities like age of onset, age/sex ratio, urban/rural difference, clinical symptoms and complications in adolescents and young diabetic patients getting treatment from Sri Manakula Vinayagar Medical College \& Hospital. RESULTS: Majority of the patients had age of onset above 25 years (83\%). Seventy nine percent of the type 1 Diabetes Mellitus (T1DM) patients had onset of disease below 30 years. Whereas, majority of the patients with type 2 diabetes (54.4\%) had onset of disease above 30 years. There were 63 males and 67 females in our study and majority of the patients had a sedentary lifestyle. Seventy percent (70\%) of the patients were from urban area. Type 2 Diabetes Mellitus (T1DM) was the commonest type of diabetes 103/130(79.3\%) followed by type 1 diabetes 19/130(14.7\%). There were 3 cases of Fibro Calculous Pancreatic Disease (FCPD) out of which 2 were from rural areas. 5 cases had steroid induced Diabetes Mellitus.73.85\% patients were asymptomatic and diabetes was detected by routine examination or when they presented to the hospital with some other illness. Family history of diabetes was present in $47.4 \%$ of type 2 diabetes, $27.8 \%$ of type 1diabetes. CONCLUSION: Majority of patients had the age of onset $>25$ years with slight female predominance. Among these type $2 \mathrm{DM}$ is the predominant type with age of onset within 30-35 yrs., majority of them were asymptomatic detected during other illness followed by type $1 \mathrm{DM}$, steroid induced DM and FCPD.

KEYWORDS: Diabetes Mellitus, Ada Criteria, Types Epidemiology, T1dm, T2dm, FCPD, Steroid Induced Dm.

INTRODUCTION: According to the ICMR-INDIAB national diabetes study, currently, there are an estimated 62.4 million individuals with diabetes in India ${ }^{1}$. This is further expected to increase to 101 million in 2030. ${ }^{1}$ Until recently, type 2 Diabetes was typically considered as a disease of the middle aged and elderly. Evidence is accumulating that onset in those aged under 30 years is increasingly common. Even children and adolescents are now becoming caught up in the diabetes epidemic. ${ }^{2}$

Although type 1 diabetes remains the main form of the disease in children worldwide, it is likely that type 2 diabetes will be the predominant form within 10 years in many ethnic groups. The global burden of type 2 diabetes is both significant and rising, with most of the increase occurring in the last two decades. The largest proportional and absolute increase is predicted to occur in developing countries. ${ }^{3}$

Incidence of type 2 diabetes in the young is increasing in many countries including India due to 
factors like obesity and lack of exercise. These children have other factors like family history of diabetes and many of them have signs of insulin resistance like Acanthosis nigricans, Hypertension, Dyslipidemia or Polycystic ovarian disease. ${ }^{4}$

Diabetes also develops at a younger age in Indians i.e., at least a decade or two earlier than Europeans. The epidemic increase in diabetes in India along with various studies on migrant and native Indians clearly indicates that Indians have an increased predilection to diabetes. This could well be due to a greater genetic predisposition to diabetes in Indians ${ }^{5}$. The incidence of monogenic forms of diabetes such as MODY is minimal all over the world 6 . In a study of Diabetes among young American Indians it was found that the incidence of type 2 Diabetes Mellitus was increasing due to obesity and life style changes. ${ }^{6}$

Various studies from India done in different geographic regions showed differences in the prevalence of various types of diabetes. In India, apart from T1DM and T2DM, there are other forms of diabetes in the young including maturity-onset diabetes of the young (MODY), fibrocalculous pancreatic diabetes (FCPD), gestational diabetes mellitus (GDM), Endocrine diabetes and the rare genetic forms of diabetes. ${ }^{7-10}$ Since the diabetes is tremendously increasing in young individuals this study was undertaken to find out the etiology and type of diabetes and the clinical and biochemical features of young patients with diabetes in our institution.

\section{AIM:}

1. To find out the type of Diabetes in patients whose age of onset is $<35$ years.

2. To study the socio-demographic characteristics and the clinical profile of young diabetics.

MATERIALS AND METHODS: This study was a descriptive study over a period of 1 year consisting of Retrospective study from June $1^{\text {st }}$ 2011-May 31 2012.

INCLUSION CRITERIA: All diabetic patients whose age of onset was more than 12 years and less than 35 years coming to medicine OPD of Sri Manakula Vinayagar Medical College \& Hospital were included in the study.

In the study a detail clinical history followed by physical examination was done in all patients. Care was taken to elicit etiology factors like nutrition, history of abdominal pain, malabsorption, drug intake etc. In all patients FBS, blood urea, Sr. creatinine, fasting lipid profile, urine routine examination and glycated $\mathrm{Hb}$ was done.

Exclusion criteria: Patients with diagnosis of gestational diabetes mellitus were not included in the study.

As like other retrospective study the data was collected from the patient's records available in the medical record department of our institution. All the data was collected according to the protocol attached. 2011 ADA criteria were used for diagnosis and categorization into various types of diabetes. ${ }^{11}$ The data obtained was tabulated and was analyzed.

RESULTS: This study was done over a period of 1 year from 01.06.2011 to 31.05 .2012 (1 year retrospective study). A total of 130 cases who had onset of diabetes before the age of 35 were included in the study. Details of the study are given below. 


\begin{tabular}{|c|c|c|c|}
\hline Age of onset & Males & Females & Total \% \\
\hline $10-15$ & - & $2(3 \%)$ & $2(1.5 \%)$ \\
\hline $16-20$ & - & $3(4.5 \%)$ & $3(2.3 \%)$ \\
\hline $21-25$ & $9(14.3 \%)$ & $8(12 \%)$ & $17(13.1 \%)$ \\
\hline $26-30$ & $20(31.7 \%)$ & $24(35.8 \%)$ & $44(33.8 \%)$ \\
\hline $31-35$ & $34(54 \%)$ & $30(44.8 \%)$ & $64(49.2 \%)$ \\
\hline Total & $63(100 \%)$ & $67(100 \%)$ & $130(100 \%)$ \\
\hline
\end{tabular}

Mean age of the group was 31.22 and Median age was 32.

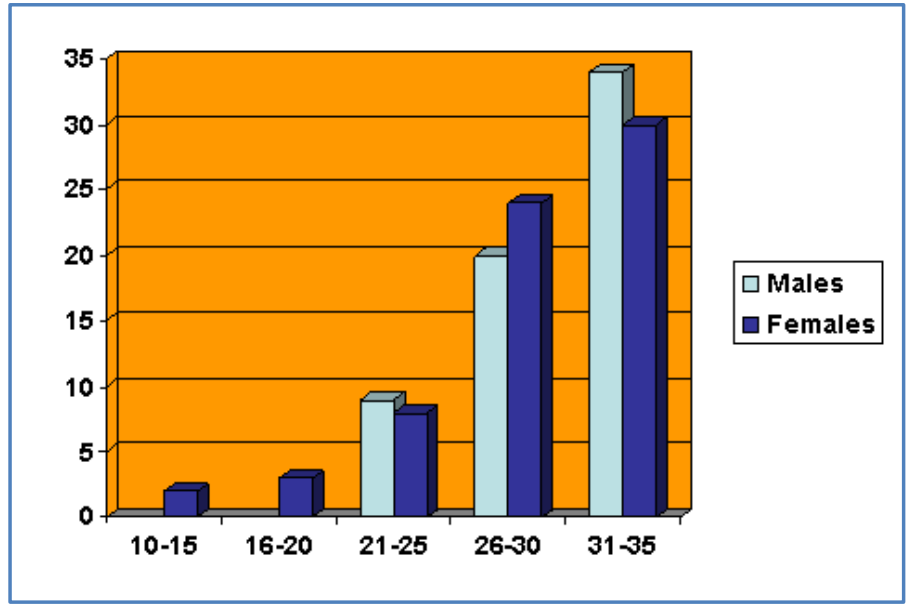

\section{FIGURE 1: Bar Diagram of and Sex Distribution Age}

Table 1 and Figure 1 shows the age of onset and sex distribution of the cases. Youngest patient was a 13 year old female and oldest was a 42 year old male. There were 22 patients who developed diabetes before the age of 25.108 patients developed diabetes above the age of 25 years. Out of this, 64 patients had onset of diabetes above age of 30.67 of the 130 (51.54\%) were females and $63(48.46 \%)$ were males.

\begin{tabular}{|l|c|}
\hline \multicolumn{1}{|c|}{ Occupation } & No \\
\hline House wife & 43 \\
\hline Business & 20 \\
\hline Student & 10 \\
\hline Shop owner & 7 \\
\hline Coolie & 7 \\
\hline Agriculture & 6 \\
\hline Driver & 4 \\
\hline Others & 10 \\
\hline \multicolumn{2}{|c|}{ Total } \\
\hline
\end{tabular}

TABLE 2: Occupation of patients 


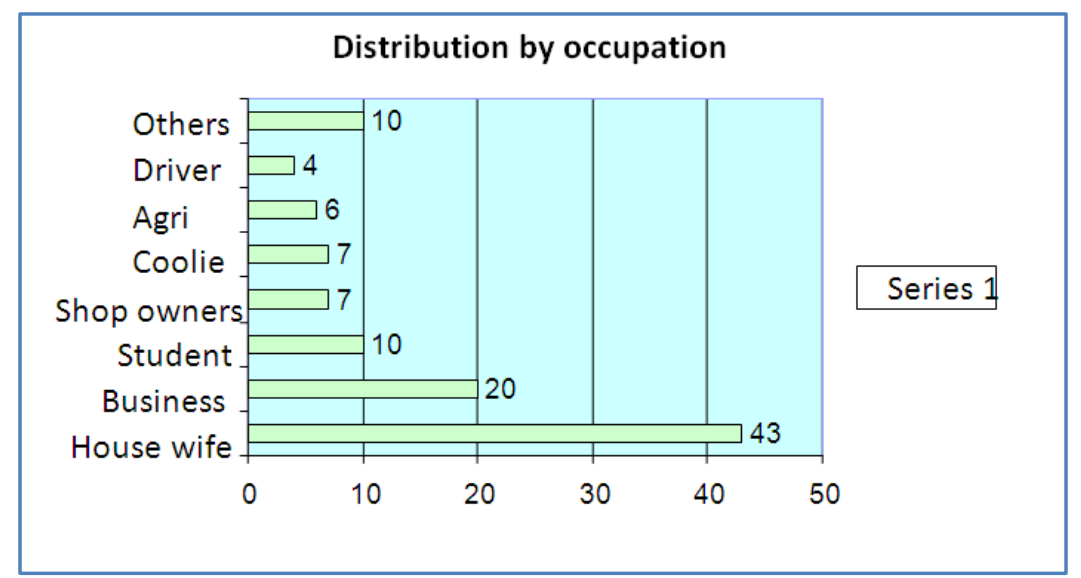

FIGURE 2: Distribution by occupation

Table 2 and Figure 2 show that most of the patients had sedentary life style oriented occupation. In 23 retrospective cases the information about occupation was not available.

\begin{tabular}{|c|c|c|c|}
\hline & Urban & Rural & Total \\
\hline Pondicherry & 55 & 17 & 72 \\
\hline Tamil Nadu & 36 & 22 & 58 \\
\hline Total & 91 & 39 & 130 \\
\hline
\end{tabular}

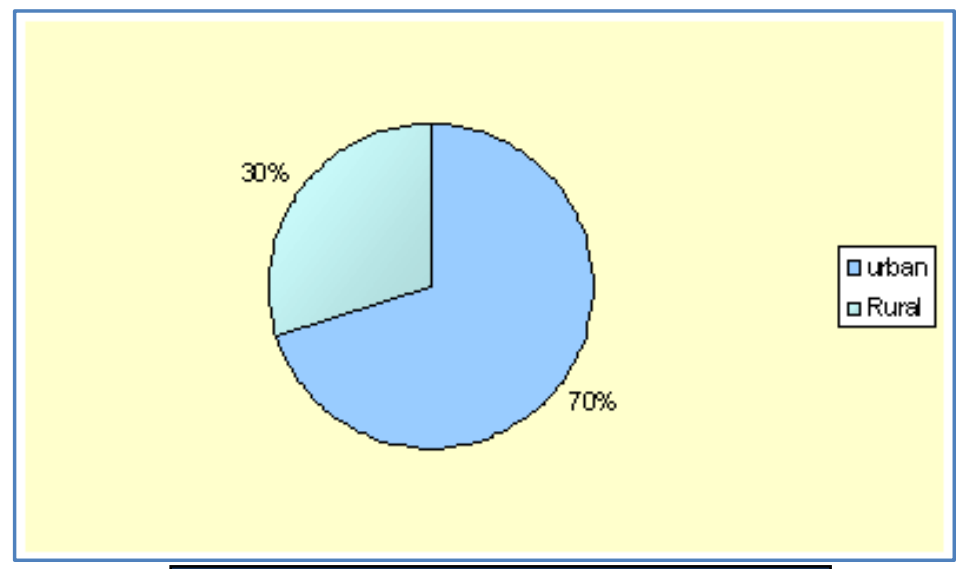

FIGURE 3A: RURAL AND URBAN

POPULATION -A COMPARISON

Table 3 and Figure $3 \mathrm{~A}$ and Figure $3 \mathrm{~B}$ show the distribution of patients according to the residence. All the patients were either from Pondicherry or nearby villages and towns of Tamilnadu. There were more patients from urban area compared to rural areas. 


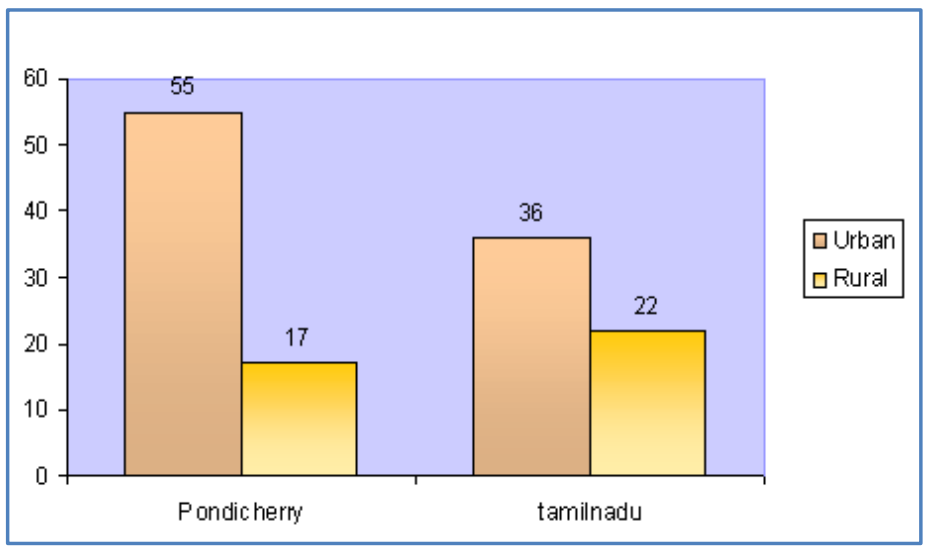

FIGURE 3B: RURAL \& URBAN PATIENTS

IN PONDICHERRY \& TAMIL NADU

72 patients were from Pondicherry and 58 patients were from Tamil Nadu. More No. of patients of both the states was from urban areas.

\begin{tabular}{|c|c|c|}
\hline Type of DM & No. of cases & $\%$ \\
\hline Type 1 & 19 & $14.62 \%$ \\
\hline Type 2 & 103 & $79.23 \%$ \\
\hline Steroid Induced diabetes mellitus & 5 & $3.85 \%$ \\
\hline FCPD & 3 & $2.30 \%$ \\
\hline Total & 130 & $100 \%$ \\
\hline
\end{tabular}

TABLE 4: Distribution by Type of Diabetes

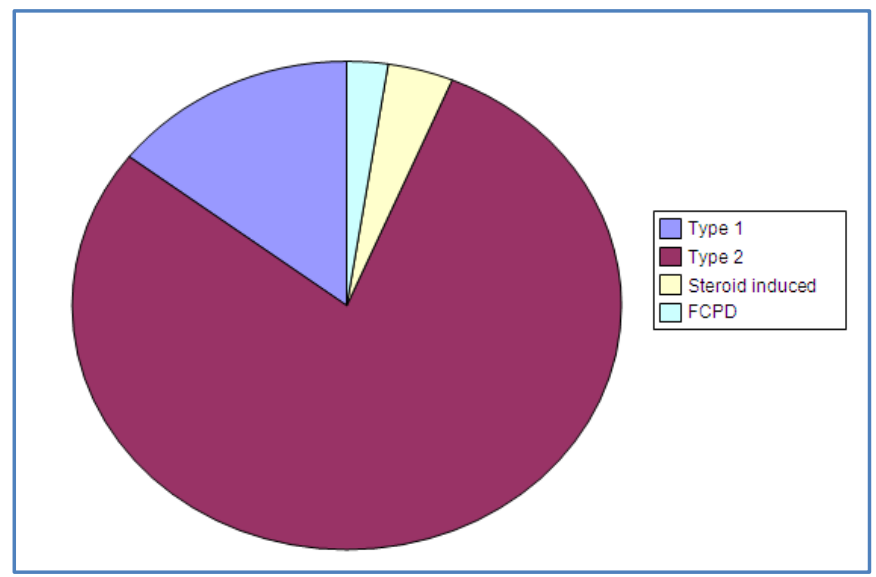

FIGURE 4: DISTRIBUTION OF VARIOUS TYPES OF DIABETES

Table 4 and Figure 4 shows the distribution of various types of diabetes of 130 patients, Type 2 DM was the commonest type accounting for 103/130 (79.23\%) followed by type 1 diabetes (14.62\%). There were 5 cases of steroid induced DM and 3 cases of FCPD. 


\begin{tabular}{|c|c|c|c|c|}
\hline Age of onset & Type I & Type II & FCPD & Steroid \\
\hline $10-15$ & $1(5.3 \%)$ & $1(0.9 \%)$ & & \\
\hline $16-20$ & $1(5.3 \%)$ & $1(0.9 \%)$ & $1(33.3 \%)$ & \\
\hline $21-25$ & $8(42.1 \%)$ & $7(6.8 \%)$ & 0 & $2(40 \%)$ \\
\hline $26-30$ & $5(26.3 \%)$ & $38(36.9 \%)$ & 0 & $1(20 \%)$ \\
\hline $31-35$ & $4(21 \%)$ & $56(54.4 \%)$ & $2(66.7 \%)$ & $2(40 \%)$ \\
\hline Total & $\mathbf{1 9}$ & $\mathbf{1 0 3}$ & $\mathbf{3}$ & $\mathbf{5}$ \\
\hline
\end{tabular}

TABLE 5: Correlation of Age of Onset \& Types of Diabetes

Table 5 shows the majority of patients with type I disease (15/19) had onset of disease below 30. In contrast majority of patients with type 2 diabetes had onset above age of 30 (53/103). Only 9 patients (8.7\%) of type 2 diabetes had onset below age of 25 , compared to $10 / 19(52.7 \%)$ of type 1 diabetes who had onset below 25 .

\begin{tabular}{|l|c|c|}
\hline & Urban & Rural \\
\hline Type 1 & 15 & 4 \\
\hline Type 2 & 71 & 32 \\
\hline Steroid Induced. DM & 4 & 1 \\
\hline FCPD & 1 & 2 \\
\hline Total & 91 & 39 \\
\hline
\end{tabular}

TABLE 6: Type of Diabetes in Rural/ Urban Population

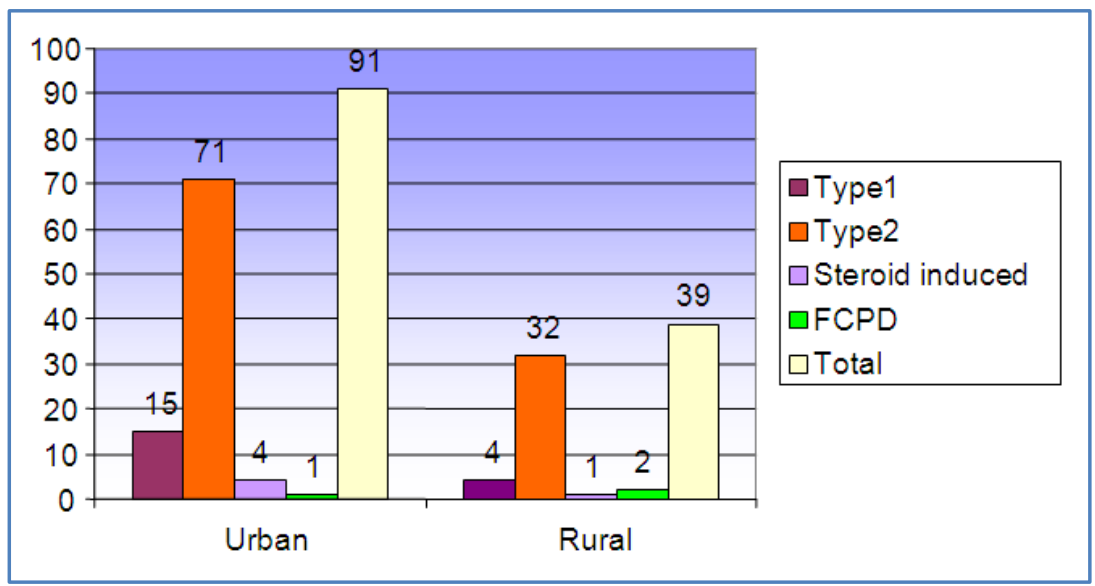

\section{FIGURE 6: TYPE OF DIABETES}

IN URBAN/RURAL AREAS

Table 6 and Figure 6 show the various types of diabetes in the rural and urban areas. The no of patients from urban area were more than that of rural areas in all types of diabetes, except in the case of FCPD where 2 out of 3 were from rural areas. 


\begin{tabular}{|l|c|c|c|}
\hline \multicolumn{1}{|c|}{ Duration } & Type 1 & Type 2 & Total \\
\hline New & 10 & 71 & 81 \\
\hline 1-5years & 6 & 22 & 28 \\
\hline$>5$ years & 3 & 10 & 13 \\
\hline & $\mathbf{1 9}$ & $\mathbf{1 0 3}$ & $\mathbf{1 2 2}$ \\
\hline
\end{tabular}

Table 7: Duration of Diabetes in Different Type of Diabetes Mellitus

Remaining 8 cases - FCPD/ Steroid induced DM were not included in the table.

Newly detected cases accounted for majority of the cases (81/122). 28 patients had duration between 1-5 years. Only 13/122 had duration more than 5 years.

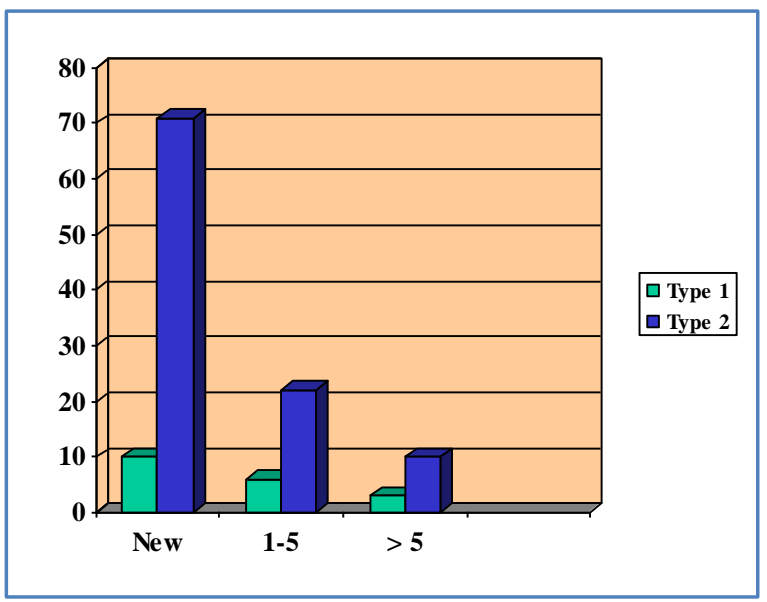

\section{FIGURE 7: DURATION OF DIABETES}

Table 7 and Figure 7 show the duration of diabetes in various types. Out of 130 patients 61 patients were newly detected cases of diabetes. There were only 13 cases with duration of diabetes more than 5 years.

\begin{tabular}{|l|c|c|}
\hline \multicolumn{1}{|c|}{ Presentation } & No. of cases & Percentage (\%) \\
\hline \multicolumn{1}{|c|}{ Asymptomatic } & $\mathbf{9 6}$ & $\mathbf{7 3 . 8 5 \%}$ \\
\hline \multicolumn{1}{|c|}{ Symptoms } & $\mathbf{3 4}$ & $\mathbf{2 6 . 1 5 \%}$ \\
\hline Polyuria & 26 & \\
\hline Polydipsia & 19 & \\
\hline Polyphagia & 11 & \\
\hline Weight loss & 16 & \\
\hline Tiredness & 24 & \\
\hline Blurring of vision & 13 & \\
\hline Delayed Wound Healing & 7 & \\
\hline Leg pain & 9 & \\
\hline Paraesthesia & 7 & \\
\hline DKA & 9 & \\
\hline \multicolumn{2}{|c|}{ Table 8: Clinical Symptoms of the Patients } \\
\hline
\end{tabular}


Table 8 shows the clinical symptoms in the patients. Majority of the cases 96/130 (74\%) were detected to have diabetes while evaluating for other conditions. Only 34 patients (26\%) had presented with typical symptoms of diabetes. Among the symptomatic patients, commonest symptoms were polyuria, polydipsia followed by tiredness.

\begin{tabular}{|c|l|c|l|}
\hline System & \multicolumn{1}{|c|}{ Symptoms } & No & Total \\
\hline CVS & Chest pain & 09 & 09 \\
\hline RS & Cough/ cold/ sputum & 16 & 16 \\
\hline \multirow{5}{*}{ GI } & Abdominal pain & 08 & \\
& Indigestion & 02 & \\
& Nausea & 06 & \\
& Vomiting & 07 & \\
& Diarrhoea & 02 & 25 \\
\hline Genital & Balanoposthitis & 04 & \\
& Vulvovaginitis & 05 & \\
& White discharge & 03 & \\
& Dysuria & 8 & \\
Urinary & Other vaginal symptoms & 2 & 22 \\
\hline \multirow{5}{*}{ Skin: } & Acanthosis & 12 & \\
& Pyoderma & 1 & \\
& Vitiligo & 1 & \\
& Lepra reaction & 1 & \multicolumn{1}{|c|}{} \\
& Psoriasis & 1 & 16 \\
\hline Others & & $\mathbf{3 3}$ & \\
\hline TABLE 9: Systemic Symptoms in Patients with DM
\end{tabular}

Table 9 shows Systemic Symptoms in Patients with DM among the systemic symptoms, Acanthosis nigricans was present in 12 patients, Balanoposthitis in 4 patients, vulvovaginitis in 5 patients.

\begin{tabular}{|l|c|}
\hline \multicolumn{1}{|c|}{ Illness } & No. of Cases \\
\hline Hypertension & 20 \\
\hline Bronchial Asthma & 3 \\
\hline Primary Infertility & 7 \\
\hline PCOD & 3 \\
\hline Hyperthyroidism & 1 \\
\hline Hypothyroidism & 4 \\
\hline Psychiatric illness & 4 \\
\hline Postpartum with H/o GDM & 3 \\
\hline
\end{tabular}

Table 10: Analysis of Associated Illness

Table 10 shows Analysis of Associated Illness. Among the associated illness Hypertension was the commonest which was present in 20 patients. Out of the 20 patients 7 patients were known 
hypertensive and 13 patients were found to have Hypertension on examination. There were 7 patients with primary infertility, 3 patients with polycystic ovarian disease and 5 patients with thyroid disorders. Three patients who had prior history of gestational diabetes mellitus were detected to have diabetes during the study. Four patients presented with h/o psychiatric illness and 3 patients had bronchial asthma along with diabetes.

\begin{tabular}{|c|c|c|c|c|}
\hline Family history & Type 1 & Type 2 & Steroid in DM & FCPD \\
\hline Yes & $5(27.8 \%)$ & $45(47.4 \%)$ & 0 & $2(66.7 \%)$ \\
\hline No & $13(72.2 \%)$ & $50(52.6 \%)$ & $5(100 \%)$ & $1(33.3 \%)$ \\
\hline Total & $\mathbf{1 8 ( 1 0 0 \% )}$ & $\mathbf{9 5 ( 1 0 0 \% )}$ & $\mathbf{5 ( 1 0 0 \% )}$ & $\mathbf{3 ( 1 0 0 \% )}$ \\
\hline \multicolumn{7}{|c}{ TABLE 11: Analysis of family history } \\
\end{tabular}

Table 11 shows the analysis of family history of diabetes in our patients. Five out of 18 patients $(27.8 \%)$ of type $1 \mathrm{DM}$ and $45 / 95$ patients (47.4\%) of type $2 \mathrm{DM}$ had positive family history. In one type I Diabetes Mellitus patients and 10 type 2 Diabetes Mellitus patients the information about family history was not available.

\begin{tabular}{|c|c|c|c|}
\hline Diet Habits & Type 1 (\%) & Type 2 \% & Total \% \\
\hline Vegetarian & $4(21)$ & $12(11.6)$ & $16(13.1)$ \\
\hline Non vegetarian & $15(79)$ & $91(88.4)$ & $106(86.8)$ \\
\hline Total & $\mathbf{1 9 ( 1 0 0 )}$ & $\mathbf{1 0 3 ( 1 0 0 )}$ & $\mathbf{1 2 2 ( 1 0 0 )}$ \\
\hline \multicolumn{4}{|c}{ TABLE 12: Diet Habits } \\
\hline
\end{tabular}

Table 12 shows the Diet Habits of patients belonging to type 1 and type 2 diabetes. There was more number of patients taking non- vegetarian diet in both the groups. Almost all the patients consumed a high carbohydrate diet with hardly any fresh fruits or vegetables.

\begin{tabular}{|l|c|}
\hline \multicolumn{1}{|c|}{ Complication } & No. of Cases \\
\hline Neuropathy & 10 \\
\hline Nephropathy & 6 \\
\hline Retinopathy & 7 \\
\hline CVA & Nil \\
\hline CAD & 8 \\
\hline DKA & 9 \\
\hline HONKC & Nil \\
\hline Hypoglycemia & 3 \\
\hline Foot ulcer & 7 \\
\hline TB & 10 \\
\hline Skin infection & 12 \\
\hline Genital infection & Tabliabetes Mellitus \\
\hline
\end{tabular}

Table 13 shows the Complications of Diabetes Mellitus. Among the complications 10 patients presented with neuropathy alone, 9 patients presented with DKA and out of this 7 patients belonged to type 1 diabetes mellitus. Eight patients presented with CAD, 7 patients with retinopathy, 6 patients with nephropathy and 2 patients with hypoglycemia. 
DISCUSSION: This study was done over a period of 1 year, retrospectively from 01.06.2011 to 31.05.2012. A total of 130 patients of diabetes mellitus who had onset of disease before the age of 35 seen in our institution were studied. Patients were either from Pondicherry or nearby towns and villages of Tamil Nadu.

AGE \& SEX DISTRIBUTION: Indian diabetics have certain peculiarities. They have increased susceptibility for diabetes and diabetes tends to occur at a young age compared to diabetics in other countries. Mean age of onset for Indian diabetics was the lowest (43.6) compared to the mean age of onset of diabetes in other Asian countries according to the diabcare Asian study. ${ }^{12}$ In our study mean age of onset was 31.22 and median age of onset was 32 .

The mean age of onset of type 1 diabetes was 26 in our study. However, we had not included patients below the age of 12 in our study. Majority of patients of (15/19) type 1 diabetes had onset of disease below 30 years. Ten out of 19 had onset of disease below 25 years of age. V P Jyostna et.al in North-Eastern India studied with 70 diabetics of less than 30 years of age and found the mean age was lowest among IDDM subjects which was 19.9 years $^{8}$. In this study other types of diabetes were rarely seen in patients younger than this.

The prevalence of diabetes tends to increase with increasing age. In our study also majority of patients had onset of diseases above the age of 30 (49.2\%). Only 22 patients $(16.9 \%)$ had age of onset below 25 years. Even out of this 9 patients were of type 2 Diabetes Mellitus. Our finding is similar to the epidemiological trend described in other studies. A study conducted among American Indians (AI) and Alaska Natives (AN) with age <35 years in United States from 1994 to 2004 showed high numbers of young diabetics. Prevalence of diagnosed diabetes increased with age and in 2004 ranged from $2.2 / 1000$ population among AI/AN aged $<15$ years to 46.8/1000 population among those aged 25-34 years. ${ }^{13}$ Similarly in another study conducted by C.Y. PAN et.al among 919 newly diagnosed patients aged between $12-40$ years, the mean age of onset was $31.6 \pm 7.2$ years with majority (66\%) in the 31 40 years age group. ${ }^{12}$

In our study there were 67 females and 63 males with male to female ratio of 0.9. In a study conducted among American Indians and in Alaska natives less than 35 years in USA in 2004 the age adjusted prevalence of diagnosed diabetes was 20.2 per 1000 among females and 13.7 among males. During 1994-2004 prevalence of diagnosed diabetes was greater among females than males in all age groups. Prevalence also increased steadily for both sex and in all age groups except those aged 25-34 years in which males were predominant ${ }^{13}$. This was similar to the finding in our study in which as the age advances number of males were increasing. In a Asian study done in young diabetes by C.Y PAN et.al $66 \%$ were male with mean age of onset of $31.6 \pm-7.2$ years and majority of them (67\%) were between $31-40$ years. ${ }^{12}$

There was slight majority of female patients in our study which could be due to life style, food habits and lack of occupation among females. Even within the house their physical activities was very much reduced due to the discoveries of home appliances which does not require much physical activities.

DISTRIBUTION OF PATIENTS: RURAL/ URBAN: When rural and urban population were compared, number of patients in the urban area (70\%) was higher than that in the rural population (30\%). This is supported by a study in different regions of Asia by C Y PAN et.al in which, both Type 1 \& Type 2 Diabetes Mellitus in urban area was higher than the rural areas. ${ }^{12}$ Studies conducted in India in the last 
decade has highlighted that not only is the prevalence of type 2 diabetes high, but also that it is increasing rapidly in the urban population. For e.g. A study conducted by Ramachandran et.al in Madras in 1992 showed a prevalence of $8.2 \%$ in urban areas compared to $2.4 \%$ in rural areas ${ }^{4}$. In another study done by same author in 2000 by National Urban Diabetic Survey showed prevalence of $12.1 \%$ in urban areas. ${ }^{4}$ Similarly Ramankutty et.al in 2001 in Kerala reported that the prevalence of diabetes in urban areas was $12.4 \%$ compared to $2.5 \%$ in rural areas. ${ }^{14}$

Urbanization has brought several changes in the lifestyle in most urban areas in India .These changes include consumption of excess calories, reduction in intake of complex carbohydrates with increased consumption of simple sugars and fats. Moreover availability of energy saving methods of transport and labor have resulted in severely reduced physical activity.

This was shown in recent population study in Chennai (CUPS) that the total activity level considering the activity at work and during leisure time was very low, especially in women. ${ }^{15}$

DISTRIBUTION BY OCCUPATION: People who belong to the sedentary life style oriented occupation have high incidence of diabetes in young population. This suggests that the life style changes and occupation are important risk factors for developing type 2 DM in adolescents and young adults. This supports the previous study results that reduced physical activity, development of central obesity and insulin resistance were the main reasons for increasing trend of type 2 DM among adolescents and young adults. This was clearly shown in Chennai Urban Population Study (CUPS) by V. Mohan et al in which he studied two groups of patients in Chennai from two areas namely Tirumangalam and $\mathrm{T}$. Nagar. Most of the residents of Thirumangalam were businessmen, professionals, executives and clerical workers while the T. Nagar residents were mostly manual laborers, maid servants and some clerical workers. The mean monthly income of family of Thirumangalam was Rs. 8075/- while that of a T. Nagar was Rs. 1, 399. Subjects with negative family history of diabetes but higher socio economic status had higher risk for glucose intolerance compared to subjects of lower socioeconomic status and no family history.

Similarly, those with higher SES and positive family history of diabetes had five times high prevalence of glucose intolerance compared to subjects of lower SES and no family history. Prevalence of diabetes, IGT and glucose intolerance were computed against grades of physical activity. Prevalence of diabetes was significantly higher among subjects with light grade activity (17\%) compared to moderate grade $(9.7 \%)$ and heavy grade activity (5.6\%). The prevalence of IGT was higher among subjects with moderate (7.8\%) and light grades of physical activity $(6.2 \%)$ compared to heavy grade activity (2.5\%). Overall, the prevalence of glucose intolerance was significantly higher among subjects who had light grade activity (23.2\%) compared to moderate $(17.5 \%)$ and heavy grade activity $(8.1 \%)$. sedentary life style (even visit to farms is usually on motorbike) and consumption of oil rich foods were two factors described by the authors responsible for the increasing incidence of diabetes in the young 15 .

DISTRIBUTION BY TYPE OF DIABETES: Type 2 Diabetes Mellitus was the commonest type found in our study comprising 79.23\%. Type 1 Diabetes Mellitus was found only in 19 patients which was $14.62 \%$ followed by steroid induced DM 3.85\% and FCPD $2.30 \%$.

The distribution of various types of diabetes differs in various geographical areas of the world. For example the incidence of T1DM is highest in Finland whereas the majority of the population in Asian continent have a very low incidence of T1DM. In a study from USA, in Alaska natives and 
migrated Indians and also in the region of Montana and Wyoming a rising prevalence of type 2 DM among young American Indians was found, due to their lifestyle changes and changed food habits like, excessive consumption of Coca-Cola drinks ${ }^{13}$. In another Asian study conducted in China, Hong Kong, India, Malaysia and Singapore also a high and rising prevalence of type 2 diabetes in young populations was found. ${ }^{12}$ Kitasayampoo et al in their study of 151 cases of diabetes in Thailand, who were less than 35 years found that $38.4 \%$ belonged to NIDDM, 36.4\% to MRDM, 36.4\% to IDDM, 9.9\% to secondary diabetes mellitus and $12.6 \%$ to unclassified category. ${ }^{16}$

Studies from India also show that different types of diabetes are common in different regions. A study conducted by Jyostna et al in North eastern Indian region in 70 diabetics less than 30 years showed FCPD to be the commonest accounting for 32.9\%, IDDM was seen in 28.6\%, MMDM 21.4\% and NIDDM $17.11 \%{ }^{8}$. In contrast, Ramachandran et al in their study conducted in Chennai among 314 patients found that majority of patients (57.7\%) were of type $2 \mathrm{DM}, 22 \%$ were type $1 \mathrm{DM}, 5 \%$ were MRDM and 4\% were pancreatic diabetes ${ }^{7}$. Samal et al in his study in Orissa showed Malnutrition related diabetes (MMDM) was the commonest ${ }^{10}$. Zargar et al in his study in Srinagar, Kashmir showed type 1 DM was the commonest. ${ }^{9}$

CLINICAL PRESENTATION: Type 2 Diabetes is a silent disease. By the time the symptoms develop the disease would have been there for about 10 years and, it is not uncommon to detect complications even at the onset of disease. In contrast type 1 diabetes tends to occur acutely and majority of the patients are symptomatic. Many present for the first time with diabetic ketoacidosis. Out of 130 cases, only $34(26.15 \%)$ cases presented with typical symptoms of diabetes and majority of the patients were found to have diabetes by routine investigation when they presented with some other illness. Among the patients who presented with typical symptoms of Diabetes Mellitus, polyuria (26/34) was the commonest symptom, followed by tiredness (24/34) and polydipsia 19/34 cases. Weight loss also was found in some patients. Apart from the typical diabetic symptoms, many patients presented with systemic symptoms.

Many were tested for diabetes when they presented with skin infections or genitourinary infections. Nine patients presented with DKA out of which seven patients belonged to type 1 diabetes. Acanthosis nigricans was detected in 12 patients which is being considered as one of the markers of the insulin resistance. History of steroid intake was present in 11 cases. Only five cases developed diabetes after steroid intake. Insulin resistance and type 2 Diabetes Mellitus are known to be associated with infertility. Seven patients in our study had primary infertility and 3 patients had PCOD. Three cases had history of GDM.

In a study conducted by C Y Pan et al majority of patients had symptoms. In their study 79\% were symptomatic at presentation with small variation between three ethnic groups (76-83\%). Ten percent had ketoacidosis at presentation while most presented with hyperglycemic symptoms, mainly thirst (65\%), weight loss (44\%) and lethargy (39\%). ${ }^{12}$

FAMILY HISTORY DIABETES MELLITUS: Type 2 Diabetes Mellitus has been described as an inherited disease, with more than $90 \%$ incidence rate in monozygotic twins. Asian Indians have strong familial aggregation of diabetes with high prevalence of diabetes among the first degree relatives and vertical transmission through 2 or more generations. An analysis of family history in the type 2 diabetes patients attending the diabetes research centre, Madras, India showed that 54\% of the probands had a parent with known diabetes and an additional $22.8 \%$ had siblings with diabetes. 
The prevalence of diabetes among offspring with one diabetic parent was $36 \%$, which increased to $54 \%$ with positive family history of diabetes on the non-diabetic parent also. The prevalence rate $(62 \%)$ and the risk rate $(73 \%)$ increased further when both parents had diabetes ${ }^{17}$. In CUPS study, V Mohan et. al showed high prevalence of glucose intolerance among subjects who had both parents with diabetes (55\%) which was significantly higher than the prevalence in patients with one parent having diabetes $(22.1 \% \mathrm{p}=0.005)$ and those with no family history $(15.6 \% \mathrm{p}<0.0001)$. Several studies clearly demonstrate that "Double Gene Dose Effect" (both parents diabetic) is high among Indians. In many communities in South India consanguinity is prevalent, increasing the chance of Double Gene Dose Effect.15, 16

In our study a positive family history was present in 45/ 95 patients (47.4\%) of type 2 Diabetes Mellitus and 5/18 (27.8\%) of type I Diabetes Mellitus. None of the 5 patients with steroid induced diabetes had family history. There were 14 patients with history of diabetes in both parents out of which 2 were type 1 diabetes. In the study done by CY Pan $45 \%$ of the subjects had positive family history. Family history was found more in Indians (60\%) compared to Chinese \& Malays. ${ }^{12}$

There was no family history in $52.6 \%$ of our type 2 patients and $72.2 \%$ type 1 patients showing the importance of social and environmental factors, life style and food habits in the etiology of diabetes.

DIETARY HABITS AND DIABETES: Change in diet from the traditional diet in the rural areas when people migrate to urban areas has been implicated in the expression of diabetes. In our study more patients took non vegetarian diet than vegetarian diet. Our patient's diet mainly consisted of rice or rice based food (Idlis, dosas, pongal etc.). Patients did not include fresh vegetables or fruits in the diet.

A study done in Boston, by Harvard school of public health and Brigham Women's hospital, investigators have found that women who have a diet with a high glycemic load (carbohydrate that increase blood glucose level) and low intake of cereal fibres have $2 \frac{1}{2} 2$ times the risk of developing adult onset diabetes compared to women with a low glycemic load and high cereal intake.18

COMPLICATIONS OF DIABETES: In the case of type 1 diabetes diabetic ketoacidodsis was the commonest complication encountered. Out of the 9 patients who had DKA 7 patients were of type 1 diabetes. Neuropathy, retinopathy and CAD were seen mainly in type 2 diabetic patients.

Theresa et al in a study conducted among newly diagnosed type 2 diabetes found that young diabetics were likely to develop similar microvascular complications as that seen in adult diabetics, but were at a greater risk of microalbuminuria. They also found that the young patients had a marked increased relative risk of macrovascular cardiovascular complication compared with control subjects. ${ }^{19}$

Krakoff et al looked at incidence of retinopathy and nephropathy among PIMA Indians diagnosed with type 2 diabetes at $<20$ years of age(youth), 20-39 years of age (young adults) and 4059 years (older). Nephropathy was equally common in all age groups and was not related to the age of diabetes. ${ }^{20}$

In a study by the diabetes research centre showed retinopathy $(23.7 \%)$ is high among the Indian type 2 diabetics. They also had peripheral neuropathy (27.5\%), cardiovascular disease $11.4 \%$, PVD 4\%, CVA $0.9 \%$ and hypertension 38.0\%. A study by Mohan et al. in south India showed a prevalence of $34.1 \%$ of retinopathy. ${ }^{21}$ 
CONCLUSION: A total of 130 patients who developed diabetes before the age of 35 were included in the study. The aim of the study was to find out the different types of diabetes and their epidemiology and also to study the clinical abnormalities like age of onset, age/sex ratio, urban/rural difference, clinical symptoms and complications in adolescents and young diabetic patients getting treatment from our institution.

Majority of the patients had age of onset above 25 years (83\%). Seventy nine percent of the type 1 diabetes patients had onset of disease below 30 years. Whereas, majority of the patients with type 2 diabetes (54.4\%) had onset of disease above 30 years. There were 63 males and 67 females in our study and majority of the patients had a sedentary lifestyle. Seventy percent of the patients were from urban area. Type 2 Diabetes was the commonest type of diabetes 103/130 (79.3\%) followed by type 1 diabetes 19/130(14.7\%). There were 3 cases of FCPD out of which 2 were from rural areas. 5 cases had steroid induced diabetes. $73.85 \%$ patients were asymptomatic and diabetes was detected by routine examination or when they presented to the hospital with some other illness. Family history of diabetes was present in $47.4 \%$ of type 2 diabetes, $27.8 \%$ of type 1 diabetes.

\section{BIBLIOGRAPHY:}

1. Anjana RM, Pradeepa R, Deepa $M$, et al. Prevalence of diabetes and prediabetes (impaired fasting glucose and/or impaired glucose tolerance) in rural and urban India: phase 1 results of the Indian Council of Medical Research-INDia DIABetes (ICMR INDIAB) study. Diabetologia. 2011; 54(12):3022-7.

2. American Diabetes Association: Type 2 diabetes in children and adolescents. Diabetes Care 2000; 23:381-389.

3. King H, Aubert RE, Herman WH. Global burden of diabetes, 1995-2025: prevalence, numerical estimates, and projections. Diabetes Care 21:1414-1431, 1998

4. Ramachandran A, Snehalatha C, Viswanathan M. Prevalence of glucose intolerance in Asian Indians. Urban-Rural difference and significance of upper body adiposity. Diabetic care, 1992; 15:1348-1355.

5. Stefan S, Fajans, Greme I, Bell, Kenineth S, Polonsky. Molecular mechanism and clinical pathophysiology of maturity onset diabetes of the young. NEJM 2001; Volume 345:971-980.

6. Moore KR, Harwell TS, McDowell JM, Hegerson SD, Gohdes D, Burrows NR. Diabetes among Young American Indians-Montana and Wyoming. MMWR 2003 Nov; 62 (46):1127-1129.

7. Ramachandran A, Mohan V, Snehalatha, Bharani G, Chinnikrishnudu, Mohan R et al. Clinical features of diabetes in the young as seen at a diabetes center in South India. Diabetes Res Clin Pract; 1988 Jan 7:4(2):117-25.

8. Jyostna VP, Singh SK, Gopal D, Unnikrishnan AG, Agrawal, et al. Clinical and Biochemical Profiles of young diabetes in North Eastern India. J Assoc Physicians India 2002; Sep: 50:1130-1134.

9. Zargar AH, Bhat MH, Laway BA, Masoodi SR. Clinical and biochemical profile of early onset diabetes mellitus: data from a tertiary care centre in the Indian sub-continent. J Postgrad Med 2001; 47:27-9.

10. Samal KC, Kanungo A, Sanjeevi CB. Clinical epidemiological and biochemical profile of malnutrition modulated Diabetes mellitus. Ann. N. Y. Acad. sci. 958:131-137, 2002.

11. American Diabetes Association. Diagnosis and classification of Diabetes mellitus. Diabetes Care 2011; 34(1): S62-S69. 
12. Pan CY, So W Y, Khalid A K, Mohan V, Thai AC et al. Metabolic, immunological and clinical characteristics in newly diagnosed Asian diabetes patients aged 12-40 years. Diabetic medicine 2004; 21:1007-1013.

13. Diagnosed Diabetes among American Indians and Alaska natives Aged $<35$ years, Indian Health Services and CDC, USA. MMWR Nov 2006/55(44); 12011203.

14. Ramankutty, Soman C.R, Joseph A, Pisharody R, Vijayakumar K. Type 2 diabetes in southern part of India. Natl Med J India 2000; 13:287-292.

15. Mohan V, Shanthirani CS, Deepa R. Glucose intolerance (Diabetes and IGT) in a selected south Indian population with special reference to Family history, obesity and life style factors-The Chennai Urban Population Study (CUPS 140.JAPI, Vol 51, Aug 2003;771-774.

16. Kiatsayompoo S, Lueprasitsakul W, Bhuripanyo P, Graisopa S. Diabetes Mellitus in the young in Srinagarind Hospital. J Med Asso Thai 1993 May; 76(5): 247-51.

17. Ramachandran A, Mohan V, Snehalatha C and Viswanathan M. Prevalence on Non- insulin dependent Diabetes mellitus in Asian Indian families with single diabetic parent. Diabetes Research and Clinical practice 4; 241-245, 1998.

18. Boston; MA study by Harvard School and public health and Brigham Women's hospital investigations. Dietary factors influence diabetes risk Harvard School and Public health relation: $1-2 ; 1997$

19. Hiller TA, Pedula KI. Complication in young adults with early-onset type 2 diabetes care 26; 2999-3005: 2003.

20. Kratkoft J, Lindsay RS, Looker HC et al. Incidence of retinopathy and Nephropathy in youth onset compared with an adult-onset type 2 diabetes. Diabetes care 26:76-81, 2003.

21. Ramachandran A, Snehalatha C and Vijay Viswanathan. Burden of type 2 diabetes and its complications-The Indian scenario. CURRENT SCIENCE, VOL.83. NO.12, DEC 2002:1-10.

\section{AUTHORS:}

1. Suresh K.

2. Maliyappa Vijay Kumar

3. Badrinath A. K.

\section{PARTICULARS OF CONTRIBUTORS:}

1. Assistant Professor, Department of General Medicine, Sri Manakula Vinayagar Medical College and Hospital, Puducherry.

2. Assistant Professor, Department of General Medicine, Sri Manakula Vinayagar Medical College and Hospital, Puducherry.

3. Professor and HOD, Department of General Medicine, Sri Manakula Vinayagar Medical College and Hospital, Puducherry.

\section{NAME ADDRESS EMAIL ID OF THE CORRESPONDING AUTHOR:}

Dr. Suresh K, Assistant Professor, Department of General Medicine, Sri Manakula Vinayagar Medical College and Hospital, Kalitheerthalkuppam, Madagadipet, Puducherry - 605107. E-mail: sureshsuchu06@gmaill.com

Date of Submission: 10/02/2014. Date of Peer Review: 11/02/2014. Date of Acceptance: 18/02/2014. Date of Publishing: 28/02/2014. 